\title{
SMALL INTERSTITIAL DELETION OF THE LONG ARM OF CHROMOSOME 2 (2q24.3): FURTHER DELINEATION OF 2q MEDIAL MONOSOMY SYNDROME
}

\author{
Yasutsugu ChInen, * Takaya ToHma, Yoshinori Izumikawa, \\ Tetsu IHA, Yoshinobu GoYa, and Kenji NaRitomi \\ Department of Pediatrics, University of the Ryukyus School of Medicine, \\ 207 Uehara, Nishihara, Okinawa 903-01, Japan
}

\begin{abstract}
Summary We report on a female infant with an interstitial deletion involving $2 \mathrm{q} 24.3$. She had multiple congenital anomalies similar to those in patients with $\operatorname{del}(2)(\mathrm{q} 31 \mathrm{q} 33)$ except for an occipital encephalocele. As a result of comparison of clinical findings among interstitial $2 q$ deletions, a distinct $2 \mathrm{q}$ medial monosomy syndrome may be delineable in association with a deletion of $2 \mathrm{q} 31$.

Key Words chromosomal aberration, $2 \mathrm{q}$ medial monosomy, encephalocele
\end{abstract}

\section{INTRODUCTION}

Since Warter et al. (1976) first reported an individual with interstitial deletion of the long arm of chromosome 2, almost 30 patients, most frequently those with a $\operatorname{del}(2)(\mathrm{q} 31 \mathrm{q} 33)$, have been reported (Boles et al., 1995). A distinct phenotypekaryotype correlation has only been suggested in patients with $\operatorname{del}(2)(\mathrm{q} 31 \mathrm{q} 33)$ (Ramer et al., 1989). We report here on an additional patient with a small interstitial deletion of band $2 \mathrm{q} 24.3$. This tiny deletion was detected by assistance with our original computerized database for birth defects.

\section{CLINICAL REPORT}

The proposita was the third infant born to healthy 32-year-old G3 P3 mother and 36-year-old father. Two elder children were healthy. No family histories of consanguinity, congenital anomalies, and mental deficiency as well as no medica-

Received June 5, 1996; Accepted July 8, 1996.

* To whom correspondence should be addressed. 

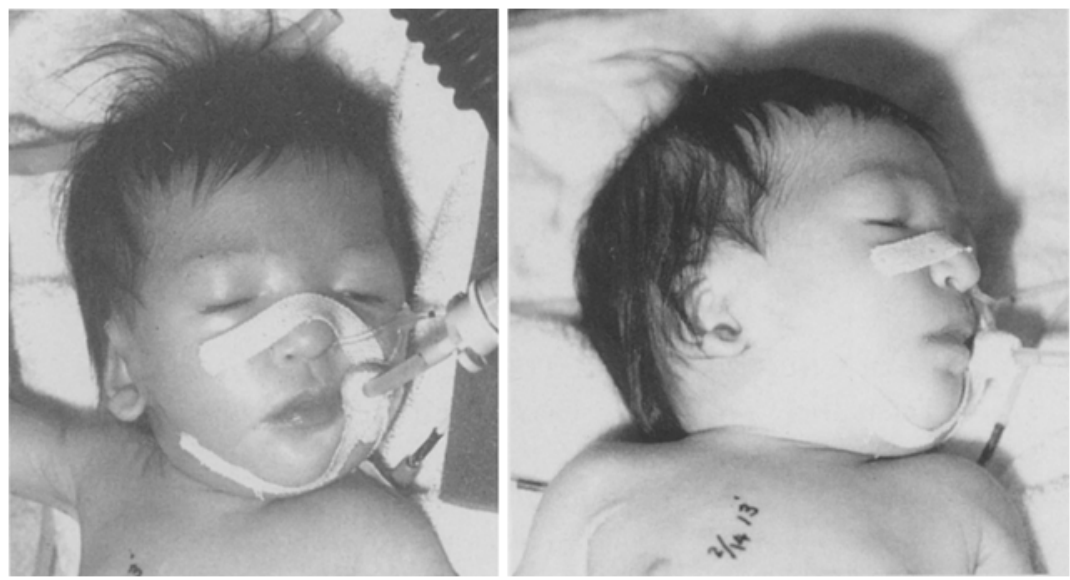

Fig. 1. Proposita at 1 month of age. Note downslanting of the palpebral fissures, ptosis, micrognathia, and low-set posteriorly rotated ears.

tions during the pregnancy were noted. The pregnancy and delivery at 38 weeks were uneventful. Her birth weight was $1,984 \mathrm{~g}(-2.8 \mathrm{SD})$. Apgar score was 9 at 1 min. At one month of age, she was referred to us for failure to thrive and multiple congenital anomalies, and admitted soon because of a progressive congestive heart failure. She was small and hypotonic. Her weight was $2,410 \mathrm{~g}(-4.2 \mathrm{SD})$, length $46 \mathrm{~cm}(-3.6 \mathrm{SD})$, and head circumference (OFC) $32.8 \mathrm{~cm}(-2.5 \mathrm{SD})$. She had a peculiar facies similar to Treacher-Collins syndrome due to marked downward slanting of the palpebral fissures, low-set and posteriorly rotated malformed ears and microretrognathia. Other findings included an occipital encephalocele, hypertelorism, short palpebral fissures, ocular ptosis, a beaked nose with its bulbous tip, uvula bifida, a short neck, widely spaced nipples, clenched hands, long fingers, pes cavus and a pansystolic harsh murmur (II/VI) (Fig. 1). Echocardiography revealed type A complete atrio-ventricular septal defect and mild coarctation of the aorta. Echograms of the brain and the abdomen revealed ventricular enlargement and normal kidneys. A skeletal roentgenogram revealed a lacunar skull defect at median posterior occiput. At two months of age, the pulmonary artery was banded to improve the progressive heart failure, but died after three days of the operation. Post-mortem examination was not permitted.

\section{DIAGNOSTIC APPROACH AND CYTOGENETICS}

Because she had a characteristic facies and multiple congenital anomalies, our original computerized database, UR-DBMS (University of the Ryukyus-Database for malformation syndromes; Naritomi, 1996) was applied to a diagnostic approach. We selected 3 distinct findings, i.e., encephalocele, cardiac defect and 


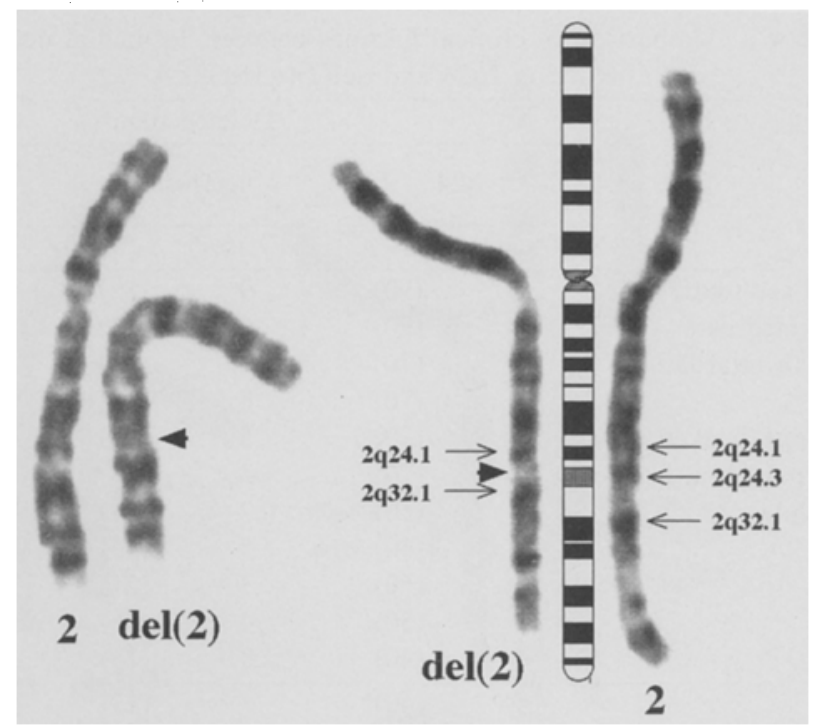

Fig. 2. Partial GTG-banded karyotype of chromosome 2. 400-band stage (left) and 550-band stage (right). Wedge indicates the breakpoint.

downward slanting of the palpebral fissures, as key words. As a result, 12 syndromes such as Noonan syndrome, Rubinstein syndrome, fetal retinoid syndrome, 2q medial monosomy, 11q2 trisomy, 13q1 trisomy, $8 \mathrm{q} 2$ trisomy, 6q21-qter trisomy, 8q22-qter trisomy/14pter-q11 trisomy, 13pter-q?31 trisomy, 13q14-q32 trisomy, and 13q?14-qter trisomy/9pter-p?22 monosomy were selected as candidates. Because no candidate malformation syndromes fitted to the manifestations of the proposita, chromosomal aberrations were highly suspected. Although an initial chromosomal analysis was reported as a normal female karyotype, a tiny deletion of chromosome 2 could not be denied. A short-term chromosome culture was performed on peripheral blood lymphocytes, and high-resolution GTG-banded chromosomes were analyzed focusing on banding patterns of chromosome $2 \mathrm{q}$. As a result, a small interstitial deletion involving the band $2 \mathrm{q} 24.3$ was detected (Fig. 2 ). The karyotype was designated as $46, X X, \operatorname{del}(2)(\mathrm{q} 24.2 \mathrm{q} 31)$. The parents were unavailable for study.

\section{DISCUSSION}

To date, 30 patients have been described with deletions of the long arm of chromosome 2. Ten of them included whole or a part of the band 2q24 (Fryns et al., 1977; McConnell et al., 1980; Shabtai et al., 1982; Bernar et al., 1984; Moller et al., 1984 (3 cases); Wamsler et al., 1991; Boles et al., 1995; present case). To confirm a phenotype-karyotype correlation among medial $2 \mathrm{q}$ monosomies, clinical findings of these patients with a deletion involving $2 q 24$ are summarized (Table 
Table 1. Comparison of clinical findings between $2 \mathrm{q}$ medial deletions involving $2 \mathrm{q} 24$ and $\operatorname{del}(2)(\mathrm{q} 31 \mathrm{q} 33)$.

\begin{tabular}{|c|c|c|c|c|c|c|}
\hline \multirow{3}{*}{ Findings } & \multicolumn{6}{|c|}{ Deleted bands } \\
\hline & \multicolumn{2}{|c|}{ q24 } & \multicolumn{2}{|c|}{$q 31-q 33$} & \multicolumn{2}{|c|}{$\begin{array}{l}\text { 2q medial } \\
\text { monosomy }\end{array}$} \\
\hline & 10 cases & $\%$ & 11 cases* & $\%$ & 21 cases & $\%$ \\
\hline Developmental retardation & 9 & $(90)$ & 9 & $(82)$ & 18 & $\overline{(86)}$ \\
\hline Low-set malformed ears & 9 & (90) & 6 & (55) & 15 & (71) \\
\hline Postnatal growth retardation & 7 & (70) & 9 & (82) & 16 & $(76)$ \\
\hline Microcephaly & 7 & (70) & 8 & (73) & 15 & (71) \\
\hline High nasal bridge/beaked nose & 7 & (70) & 6 & $(55)$ & 13 & $(62)$ \\
\hline Downslanting palpebral fissures & 7 & $(70)$ & 2 & (18) & 9 & (43) \\
\hline Cleft palate/uvula & 5 & (50) & 7 & (64) & 12 & (57) \\
\hline Micrognathia & 5 & $(50)$ & 5 & (45) & 10 & (48) \\
\hline Ptosis & 5 & $(50)$ & 3 & (27) & 8 & (38) \\
\hline Camptodactyly & 5 & $(50)$ & 4 & (36) & 9 & (43) \\
\hline IUGR & 4 & $(40)$ & 8 & (73) & 12 & (57) \\
\hline Early death & 4 & (40) & 3 & (27) & 7 & (33) \\
\hline Microphtalmia & 4 & $(40)$ & 5 & (45) & 9 & (43) \\
\hline Blepharophimosis & 4 & (40) & 3 & (27) & 7 & (33) \\
\hline Microstomia & 4 & (40) & 2 & (18) & 6 & (29) \\
\hline Clenched hands & 4 & $(40)$ & 2 & (18) & 6 & (29) \\
\hline Large forehead & 3 & (30) & 4 & (36) & 7 & (33) \\
\hline Short neck & 3 & (30) & 4 & (36) & 7 & (33) \\
\hline Sandal gap & 3 & (30) & 4 & (36) & 7 & (33) \\
\hline Clinodactyly (5) & 3 & (30) & 4 & (36) & 7 & (33) \\
\hline Syndactyly & 3 & (30) & 4 & (36) & 7 & (33) \\
\hline Hypotonia & 3 & (30) & 4 & (36) & 7 & (33) \\
\hline Cardiac defect & 3 & (30) & 3 & (18) & 6 & (29) \\
\hline Overlapped fingers & 3 & (30) & 2 & (18) & 5 & (24) \\
\hline Long fingers & 3 & (30) & 2 & (18) & 5 & (24) \\
\hline Proximal thumbs & 3 & (30) & 2 & (18) & 5 & (24) \\
\hline Seizures & 3 & (30) & 2 & (18) & 5 & (24) \\
\hline Hypoplastic nipples & 3 & (30) & 0 & $(0)$ & 3 & (14) \\
\hline $\begin{array}{l}\text { Ventricular enlargement/ } \\
\text { cerebral atrophy }\end{array}$ & 2 & (20) & 5 & (45) & 7 & (33) \\
\hline Talipes & 2 & (20) & 3 & (27) & 5 & (24) \\
\hline Encephalocele & 2 & (20) & 0 & $(0)$ & 2 & (10) \\
\hline Maxillary hypoplasia & 0 & $(0)$ & 4 & (36) & 4 & (19) \\
\hline
\end{tabular}

* Benson et al., 1986; Taysi et al., 1981; Al-Awadi et al., 1983; Franceschini et al, 1983; Young et al., 1983; Buchanan et al., 1983; Pai et al., 1983; Markovic et al., 1985; Glass et al., 1989; Ramer et al., 1989.

1), and compared with those found in reported patients with a $\operatorname{del}(2)(\mathrm{q} 31 \mathrm{q} 33)$, in which a clear phenotype-karyotype correlation has been suggested (Ramer et al., 1989). As a result, the cardinal findings and their frequencies are almost similar between the two. Because the smallest region of overlap is located at a band $2 \mathrm{q} 31$, 
we may define a $2 q$ medial monosomy syndrome associated with a deletion of $2 q 31$. The common cardinal findings of this $2 q$ medial monosomy consist of intrauterine and postnatal growth retardation, developmental and mental retardation, microcephaly, low-set malformed ears, a beaked nose with a high nasal bridge, downward slanting of the palpebral fissures, micrognathia, a cleft palate or cleft uvula, ptosis, and clenched hands or camptodactyly. In addition, the overall phenotype seems similar to that of trisomy 18 as mentioned previously (McConnell et al., 1980). Encephalocele is found only in two patients with a deletion involving 2q24.2 (McConnell et al., 1980, present case). Hypoplastic nipples are found only in three patients with a deletion involving 2q24 (Fryns et al., 1977; McConnell et al., 1980; Shabtai et al., 1982). The phenotype of distal 2q deletions is mild and apparently distinct from that of medial $2 q$ deletion (Fisher et al., 1994). Few cases of proximal $2 q$ deletions have been reported with more severe internal malformations (Antich et al., 1981; Fryns et al., 1977).

\section{REFERENCES}

Al-Awadi SA, Farag TI, Naguib K, Teebi A, Cuschieri A, Al-Othman S, Sundareshan T (1983): Interstitial deletion of the long arm of chromosome 2: del(2)(q31q33). J Med Genet 20: 464465

Antich J, Carbonell X, Clusellas N (1981): De novo interstitial deletion of the long arm of chromosome 2 in a malformed newborn karyotype: 46,XY,del(2)(q12q14). Clin Genet 19: 489

Benson K, Gordon M, Wassman ER, Chung T (1986): Interstitial deletion of the long arm of chromosome 2 in a malformed infant with karyotype 46,XX,del(2)(q31q33). Am J Med Genet 25: 405-411

Bernar J, Sparkes R, Allensworth S (1984): Interstitial deletion 2q24.3: case report with high resolution banding. J Med Genet 22: 226-228

Boles RG, Pober BR, Gibson LH, Willis CR, McGrath J, Roberts DJ, Yang-Feng TL (1995): Deletion of chromosome 2q24-q31 causes characteristic digital anomalies: case report and review. Am J Med 55: 155-160

Buchanan P, Rhodes RL, Stevenson CE (1983): Interstitial deletion 2q31-q33. Am J Med Genet 15: $121-126$

Fisher AM, Ellis KH, Browne CE, Barber JCK, Barker M, Kennedy CR, Foley H, Patton MA (1994): Small terminal deletions of the long arm of chromosome 2: two new cases. Am J Med Genet 53: 366-369

Franceschini P, Silengo MC, Davi G, Biano R, Biagioli M (1983): Interstitial deletion of the long arm of chromosome 2 (q31q33) in a girl with multiple anomalies and mental retardation. Hum Genet 64: 98

Fryns JP, Van Bosstraeten B, Malbrain H, Van den Berghe H (1977): Interstitial deletion of the long arm of chromosome 2 in a polymalformed newborn-karyotype: $46, \mathrm{XX}$, del(2)(q21;q24). Hum Genet 39: 233-238

Glass IA, Swindlehurst CA, Aitken DA, McCrea W, Boyd E (1989): Interstitial deletion of the long arm of chromosome 2 with normal levels of isocitrate dehydrogenase. J Med Genet 26: $127-140$

Markovic S, Krstic M, Sulovic V, Radojkovic Z, Adzic S (1985): Interstitial deletion of chromosome 2. J Med Genet 22: 154-155

McConnell TS, Kornfeld M, McClellan G, Aase J (1980): Partial deletion of chromosome 2

Vol. 41, No. 3, 1996 
mimicking a phenotype of trisomy 18: case report with autopsy. Hum Pathol 11: 202-205

Moller M, Garcia-Cruz D, Rivera H, Sánchez-Corona J, Cantú JM (1984): Pure monosomy and trisomy $2 \mathrm{q} 24.1 \rightarrow \mathrm{q} 3105$ due to an inv ins $(7 ; 2)(\mathrm{q} 21.2 ; \mathrm{q} 3105 \mathrm{q} 24.2)$ segregating in four generations. Hum Genet 68: 77-86

Naritomi K (1996); University of the Ryukyus-Database for malformation syndromes, Ver. 3.1. Department of Pediatrics, University of the Ryukyus, Nishihara

Pai GS, Rogers JF, Sommer A (1983): Identical multiple congenital anomalies/Mental retardation (MCA/MR) syndrome due to $\operatorname{del}(2)(\mathrm{q} 32)$ in two sisters with intrachromosomal insertional translocation in their father. Am J Med Genet 14: 189-195

Ramer JC, Ladda RL, Frankel CA, Beckford A (1989): A review of phenotype-karyotype correlations in individuals with interstitial deletions of the long arm of chromosome 2 . Am J Med Genet 32: 359-363

Shabtai F, Klar D, Halbrecht I (1982): Partial monosomy of chromosome 2. Delineable syndrome of deletion 2 (q23-q31). Ann Génét 25: 156-158

Taysi K, Dengler DR, Jones LA, Heersma JR (1981): Interstitial deletion of the long arm of chromosome 2. Case report and review of literature. Ann Génét 24: 245-247

Wamsler C, Muller B, Freyberger G, Schmid M (1991): Interstitial deletion del(2)(q24q31) with a phenotype similar to del(2)(q31q33). Am J Med Genet 39: 204-206

Warter S, Lausecker C, Pennerath A (1976): Etude chromosomique et clinique d'une fillette porteuse d'une délétion (2)(q31q36). Hum Genet 32: 225-227

Young RS, Shapiro SD, Hansen K, Hine RK, Rainosek D, Guerra FA (1983): Deletion 2q: two new cases with karyotypes 46,XY,del(2)(q31q33) and 46,XX,del(2)(q36). J Med Genet 20: $199-202$ 